\title{
Factors associated with sepsis development in 606 Spanish adult patients with cellulitis
}

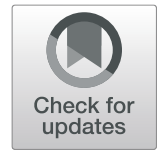

J. Collazos ${ }^{1}$, B. de la Fuente ${ }^{2}$, J. de la Fuente 3 , A. García ${ }^{4}$, H. Gómez ${ }^{4}$, C. Menéndez ${ }^{4}$, H. Enríquez ${ }^{3}$, P. Sánchez ${ }^{3}$, M. Alonso ${ }^{3}$, I. López-Cruz ${ }^{5}$, M. Martín-Regidor ${ }^{6}$, A. Martínez-Alonso ${ }^{6}$, J. Guerra ${ }^{6}$, A. Artero ${ }^{5}$, M. Blanes ${ }^{7}$ and V. Asensi ${ }^{4,8^{*}}$ (D)

\begin{abstract}
Background: Cellulitis, a frequent cause of admission of adult patients to medical wards, occasionally evolves to sepsis. In this study we analyze the factors related to sepsis development.

Methods: Prospective and observational study of 606 adult patients with cellulitis admitted to several Spanish hospitals. Comorbidities, microbiological, clinical, lab, diagnostic, and treatment data were analyzed. Sepsis was diagnosed according to the criteria of the 2016 International Sepsis Definitions Conference. Multiple logistic regression modelling was performed to determine the variables independently associated with sepsis development.

Results: Mean age was 63.4 years and $51.8 \%$ were men. Overall 65 (10.7\%) patients developed sepsis, 7 (10.8\%) of whom died, but only $4(6.2 \%)$ due to cellulitis. Drawing of blood $(P<0.0001)$ or any $(P<0.0001)$ culture, and identification of the agent $(P=0.005)$ were more likely among patients with sepsis. These patients had also a longer duration of symptoms $(P=0.04)$, higher temperature $(P=0.03)$, more extensive cellulitis $(P=0.02)$, higher leukocyte $(P<0.0001)$ and neutrophil $(P<0.0001)$ counts, serum creatinine $(P=0.001)$, and $C R P(P=0.008)$ than patients without sepsis. Regarding therapy, patients with sepsis were more likely to undergo changes in the initial antimicrobial regimen $(P<0.0001)$, received more antimicrobials $(P<0.0001)$, received longer intravenous treatment $(P=0.03)$, and underwent surgery more commonly $(P=0.01)$ than patients without sepsis. Leukocyte counts $(P=$ 0.002), serum creatinine $(P=0.003)$, drawing of blood cultures $(P=0.004)$, change of the initial antimicrobial regimen $(P=0.007)$ and length of cellulitis $(P=0.009)$ were independently associated with sepsis development in the multivariate analysis.
\end{abstract}

Conclusions: Increased blood leukocytes and serum creatinine, blood culture drawn, modification of the initial antimicrobial regimen, and maximum length of cellulitis were associated with sepsis in these patients.

Keywords: Cellulitis, Sepsis, Outcome, Antibiotics, Surgery

* Correspondence: vasensia@gmail.com

${ }^{4}$ Infectious Diseases Unit, Hospital Universitario Central de Asturias, Oviedo, Spain

${ }^{8}$ Group of Translational Research in Infectious Diseases, Instituto de Investigación Sanitaria del Principado de Asturias (ISPA), Oviedo, Spain Full list of author information is available at the end of the article

\section{Background}

Cellulitis, a common type of skin and soft tissue infection (SSTI), is a frequent cause of admission of adult patients to medical wards in all age ranges. In a recent large study using U.S. health insurance data over 2.3 million episodes of SSTI in patients aged 0-64 years were identified between 2005 and 2010 [1]. Although 95\% of them were treated in the ambulatory setting, 209,944 patients still required hospital admission. Overall the 
incidence of SSTIs represented about 48 episodes per 1000 person years in this study, an incidence that was twice that of urinary tract infections and tenfold of that of pneumonia [1]. In the Netherlands the annual incidence of cellulitis was estimated to be 22 per 1000 inhabitants, and approximately $7 \%$ of patients with cellulitis are hospitalized [2, 3].

Cellulitis can lead to bacteremia and ultimately trigger sepsis development. The frequency of bacteremia in patients with cellulitis ranges from 2 to $21.3 \%$ among patients for whom blood cultures were available, depending on the study, setting and typology of the cases analyzed [4-16]. Taking into account that most cases of cellulitis are treated in the ambulatory setting and that blood cultures are not obtained in many hospitalized patients with less severe cellulitis, populations in which expectedly bacteremia occurs more infrequently, the overall prevalence of positive blood cultures considering the full spectrum of cellulitis would be even lower.

This expected low yield of blood cultures and the fact that blood culture results did not affect treatment in complicated cellulitis led the Infectious Diseases Society of America (IDSA) to not recommending in the current guidelines the routine performance of blood cultures in patients with cellulitis and erysipelas, except for specific populations [12, 17].

However, other studies have shown that older age, male sex, diabetes, infected devices, alcohol abuse, cirrhosis, lymphedema and diverse other comorbidities increase the probability of bacteremia and, therefore, the performance of blood cultures in these patients would be advisable [9-16, 18].

To identify the factors predisposing to bacteremia in cellulitis is an area of utmost interest for the clinician taking into account that sepsis constitutes a serious and potentially deadly complication of this SSTI infection. Although a number of studies describing the prevalence and factors related to bacteremia in cellulitis have been published, it is remarkable that after an extensive literature search we failed to find any study focused on the analysis and identification of the factors predisposing to or associated with sepsis. A recent Dutch study compared the clinical characteristics and outcome of patients with cellulitis $(n=23)$ and necrotizing fasciitis $(n=31)$ admitted to an intensive care unit [7]. In this study, patients with cellulitis were less critically ill, had more chronic comorbidities and similar short and long-term mortality than patients with necrotizing fasciitis. However, the study did not analyze the factors leading to or associated with sepsis in these patients.

All these clinical and healthcare circumstances and the lack of studies emphasize the value of identifying the factors leading to sepsis, for prevention purposes and for improving the management and outcome of SSTIs.
Consequently, the availability of studies that analyze the different parameters that could be associated with the development of sepsis in patients with cellulitis is highly desirable.

The aim of this prospective and multicenter study was to detect the parameters related to sepsis in a large sample of patients hospitalized because of cellulitis. With this purpose all patients underwent a comprehensive evaluation from a demographic, clinical, bacteriological, laboratory, radiological and therapeutic point of view.

\section{Methods}

The study population was composed of adult patients ( $\geq 18$ years) admitted from 1 January 2016 to 30 June 2017 because of cellulitis to the Internal Medicine departments of the following Spanish institutions: Hospital de Cabueñes, Gijón, Hospital Universitario Central de Asturias (HUCA), Oviedo, Hospital de Povisa, Vigo, Hospital Dr. Peset, Valencia, Hospital La Fe, Valencia, and Complejo Hospitalario de León. Cellulitis was diagnosed by means of the usual clinical criteria [3, 17, 1922], with the additional support of bacteriological and imaging data. A follow-up of 30 days after discharge was scheduled to verify the outcome of the infection. The diagnosis of sepsis was made according to the 1992 sepsis definitions [23] and the 2016 revision [24].

A large number of data was prospectively recorded for each cellulitis case, including demographic, location, predisposing factors, clinical, lab, imaging, blood/pus culture, hospitalization, outcome and treatment parameters, and evaluated in accordance with the development or not of sepsis. As the results of cultures from superficial samples, such as those of ulcers, abrasions or exudates, may be not reliable because of external contamination, only cultures obtained from purulent collections were considered in order to analyze the microbiological results at the cellulitis foci.

All patients underwent standard care and management, and no specific diagnostic or therapeutic procedures were utilized for this study. Also, the patients' identification data were concealed to the investigators not involved in their care. Consequently, no written informed consent for study enrollment was required, and a waiver was granted by the Research Ethics Committee of the Principality of Asturias.

\section{Statistical analysis}

Descriptive data are reported as percentage for categorical and mean $(95 \% \mathrm{CI})$ for continuous variables. The latter variables were transformed into their natural logarithmic values for the sole purpose of statistical analysis, because the original values did not follow a Gaussian distribution. The transformed values were backtransformed after analysis to be reported in the original 
units. Categorical variables were compared with the chisquare or the Fisher's exact tests, as appropriate, whereas the $t$-test was used for the comparison of continuous variables. Multivariate analysis was performed by means of a stepwise, conditional logistic regression to detect the parameters that were associated with the development of sepsis. Statistical tests were carried out with the SPSS (v.22) software (IBM Corporation, Armonk, NY). The level of statistical significance was established at $P<0.05$ for a two-sided test.

\section{Results}

A total of 606 adult patients with cellulitis, 65 (10.7\%) with and 541 without sepsis (89.3\%), admitted to the participating hospitals from January 2016 to June 2017 were included. Table 1 shows the demographic features, as well as the main comorbidities and potential predisposing factors for the development of cellulitis and sepsis.

Mean age was 63.3 years and $51.8 \%$ were men. Overall, $65 / 606$ (10.7\%) patients developed sepsis. There were no significant differences when comparing demographic or predisposing factors between patients with and without sepsis, although there was a trend towards an association between diabetes $(P=0.09)$ and diverse other comorbidities $(P=0.096)$ with sepsis.

The clinical, laboratory, imaging and hospitalization parameters are shown in Table 2. Patients with sepsis had a shorter duration of symptoms $(P=0.04)$, higher temperature $(P=0.03)$, and more extensive cellulitis $(P=0.02)$. From a laboratory perspective, patients with sepsis had higher leukocyte $(P<0.0001)$ and neutrophil $(P<0.0001)$ counts, serum creatinine $(P=0.001)$, and CRP $(P=0.008)$ than patients without sepsis.

No differences in imaging procedures were observed in cellulitis patients with or without sepsis. Regarding outcome, death was more common in patients with sepsis than in patients without this condition $(P=0.001)$. In addition, the cause of death was related to cellulitis more frequently in patients with sepsis compared to the remaining patients $(P=0.047)$. Septic shock developed in 5 of the 65 patients with sepsis (7.7\%) and 3 of them died.

Table 3 shows the microbiological aspects of cellulitis patients with and without sepsis. Drawing of blood $(P<$ $0.0001)$ or any $(P=0.0001)$ culture, and identification of the microbiological agent $(P=0.005)$ were more likely among patients with sepsis compared to non-septic individuals. Methicillin-resistant Staphylococcus aureus (MRSA) represented $24.6 \%$ of all isolates of $S$. aureus in either blood or pus, and $9.8 \%$ of all patients with positive cultures. Two patients with MRSA infection evolved to sepsis (13.3\% of all MRSA infections) and both survived.
Table 4 shows the treatment of cellulitis patients with and without sepsis. Regarding therapy, patients with sepsis underwent changes in their initial antimicrobial regimen more commonly $(P<0.0001)$, received more antimicrobials $(P<0.0001)$, longer intravenous treatment $(P=0.03)$ and underwent surgery more frequently $(P=$ 0.01) compared to patients without sepsis.

A logistic regression model was constructed using the variables with a $P$ value $<0.1$ in the univariate analysis, excluding death, to identify the factors independently associated with sepsis (Table 5). Increased blood leukocytes $(P=0.002)$ and serum creatinine $(P=0.003)$, blood culture drawn $(P=0.004)$, modification of the initial antimicrobial regimen $(P=0.007)$ and greater extent of the cellulitis area $(P=0.009)$ were independently associated with sepsis development in the multivariate analysis. As this model included parameters dependent, in different degrees, on the clinicians' decisions (drawing of cultures, changes in therapy, etc.), the analysis was repeated after excluding such parameters. As expected, the results were very similar, with the only substitution of neutrophil counts, expressed as percent of leukocytes, by the total leukocyte counts (now $P=0.07$ ). Thus the factors independently associated with sepsis were: serum creatinine (OR 2.335 [95\% CI 1.452-3.755], $P=0.0005$ ), extent of cellulitis (OR 1.027 [1.008-1.046], $P=0.005$ ) and neutrophil count (OR 1.052 [1.009-1.097], $P=0.02$ ).

\section{Discussion}

To our knowledge this is the first study devoted to analyze the factors related to the development of sepsis in patients with cellulitis. In our large series, blood cultures drawing, modification of the initial antimicrobial regimen, extension of cellulitis and increased blood leukocytes and creatinine were associated with this complication.

Sepsis was diagnosed in $10.7 \%$ of the hospitalized patients with cellulitis in our study, a rate very similar to the $10.77 \%$ of "bacteremia/endocarditis/septicemia/sepsis" cases reported for the subset of "abscess/cellulitis" in a study using a large administrative database [1]. On the contrary, our sepsis rate was higher than the $1.6 \%$ overall (5.3\% considering only patients with bacteremia) reported in a Spanish retrospective study of 308 patients from 1997 to 2004 with limb cellulitis and similar comorbidities as our patients [9]. However, it should be taken into account that the authors consider only cases of "severe sepsis" according to the 1992 definition [23], a denomination that was considered superfluous in the 2016 update [24]. Similarly, another study involving multiple types of SSTI, including the most severe forms, found that severe sepsis developed in $9.5 \%$ of their patients, and septic shock in 3.9\% [25]. Likewise, other authors reported that 15 out of 332 patients (4.5\%) 
Table 1 Demography and predisposing factors of patients with cellulitis

\begin{tabular}{|c|c|c|c|c|}
\hline & $\begin{array}{l}\text { All } \\
\boldsymbol{n}=606\end{array}$ & $\begin{array}{l}\text { No sepsis } \\
(\boldsymbol{n}=541)\end{array}$ & $\begin{array}{l}\text { Sepsis } \\
(\boldsymbol{n}=65)\end{array}$ & $\boldsymbol{P}$ value \\
\hline \multicolumn{5}{|c|}{ Demography \& anthropometry } \\
\hline \multicolumn{5}{|l|}{ Gender } \\
\hline Male & $314(51.8 \%)$ & $276(51.0 \%)$ & $38(58.5 \%)$ & \multirow[t]{2}{*}{0.3} \\
\hline Female & $292(48.2 \%)$ & $265(49.0 \%)$ & $27(41.5 \%)$ & \\
\hline Age (years) & $63.43(61.85-65.05)$ & $63.42(61.76-65.12)$ & $63.53(58.29-69.22)$ & 1 \\
\hline \multicolumn{5}{|l|}{ Body mass index $\left(\mathrm{kg} / \mathrm{m}^{2}\right)$} \\
\hline$(n=350)$ & $30.00(29.25-30-77)$ & $30.05(29.28-30.83)$ & $29.58(26.73-32.73)$ & 0.7 \\
\hline \multicolumn{5}{|c|}{ Predisposing factors / comorbidities } \\
\hline \multicolumn{5}{|l|}{ Prior cellulitis } \\
\hline Yes & $156(25.7 \%)$ & $139(25.7 \%)$ & $17(26.2 \%)$ & \multirow[t]{2}{*}{0.9} \\
\hline No & $450(74.3 \%)$ & $402(74.3 \%)$ & $48(73.8 \%)$ & \\
\hline \multicolumn{5}{|l|}{ Episodes of prior cellulitis } \\
\hline (Only if prior cellulitis) & $1.72(1.56-1.90)$ & $1.71(1.54-1.89)$ & $1.86(1.32-2.61)$ & 0.6 \\
\hline \multicolumn{5}{|l|}{ Episodes of prior cellulitis } \\
\hline 0 & $450(74.3 \%)$ & $402(74.3 \%)$ & $48(73.8 \%)$ & \multirow[t]{5}{*}{0.4} \\
\hline 1 & 79 (13.0\%) & $71(13.1 \%)$ & $8(12.3 \%)$ & \\
\hline 2 & $27(4.5 \%)$ & $24(4.4 \%)$ & $3(4.6 \%)$ & \\
\hline 3 & $26(4.3 \%)$ & $25(4.6 \%)$ & $1(1.5 \%)$ & \\
\hline 4 or more & $24(4.0 \%)$ & $19(3.5 \%)$ & $5(7.7 \%)$ & \\
\hline \multicolumn{5}{|l|}{ Location of prior cellulitis } \\
\hline Same location & $143(91.7 \%)$ & $129(92.8 \%)$ & $14(82.4 \%)$ & \multirow[t]{2}{*}{0.15} \\
\hline Other locations & $13(8.3 \%)$ & $10(7.2 \%)$ & $3(17.6 \%)$ & \\
\hline \multicolumn{5}{|l|}{ Prior wounds } \\
\hline Yes & $332(54.8 \%)$ & $295(54.5 \%)$ & $37(56.9 \%)$ & \multirow[t]{2}{*}{0.7} \\
\hline No & $274(45.2 \%)$ & $54.5 \%(45.5 \%)$ & $28(43.1 \%)$ & \\
\hline \multicolumn{5}{|l|}{ Type of wound } \\
\hline None & $274(45.2 \%)$ & $246(45.5 \%)$ & $28(43.1 \%)$ & \multirow[t]{8}{*}{0.8} \\
\hline Skin ulcer & $110(18.2 \%)$ & $96(17.7 \%)$ & $14(21.5 \%)$ & \\
\hline Non-surgical trauma & $108(17.8 \%)$ & $94(17.4 \%)$ & $14(21.5 \%)$ & \\
\hline Surgical & $34(5.6 \%)$ & $32(5.9 \%)$ & $2(3.1 \%)$ & \\
\hline Animal bite & $12(2.0 \%)$ & $12(2.2 \%)$ & $0(0.0 \%)$ & \\
\hline Injection & $11(1.8 \%)$ & $9(1.7 \%)$ & $2(3.1 \%)$ & \\
\hline Arthropod bite & $11(1.8 \%)$ & $10(1.8 \%)$ & $1(1.5 \%)$ & \\
\hline Others & $46(7.6 \%)$ & $42(7.8 \%)$ & $4(6.2 \%)$ & \\
\hline \multicolumn{5}{|l|}{ Prior skin lesions } \\
\hline Yes & $182(30.0 \%)$ & $164(30.3 \%)$ & $18(27.7 \%)$ & \multirow[t]{2}{*}{0.7} \\
\hline No & $424(70.0 \%)$ & $377(69.7 \%)$ & $47(72.3 \%)$ & \\
\hline \multicolumn{5}{|l|}{ Diabetes } \\
\hline Yes & $153(25.2 \%)$ & $131(24.2 \%)$ & $22(33.8 \%)$ & \multirow[t]{2}{*}{0.09} \\
\hline No & $453(74.8 \%)$ & $410(75.8 \%)$ & $43(66.2 \%)$ & \\
\hline \multicolumn{5}{|l|}{ Varices } \\
\hline Yes & $124(20.5 \%)$ & $112(20.7 \%)$ & $12(18.5 \%)$ & \multirow[t]{2}{*}{0.7} \\
\hline No & 482 (79.5\%) & 429 (79.3\%) & 53 (81.5\%) & \\
\hline
\end{tabular}


Table 1 Demography and predisposing factors of patients with cellulitis (Continued)

\begin{tabular}{|c|c|c|c|c|}
\hline & $\begin{array}{l}\text { All } \\
\boldsymbol{n}=606\end{array}$ & $\begin{array}{l}\text { No sepsis } \\
(\boldsymbol{n}=541)\end{array}$ & $\begin{array}{l}\text { Sepsis } \\
(\boldsymbol{n}=65)\end{array}$ & $\boldsymbol{P}$ value \\
\hline \multicolumn{5}{|c|}{ Prior deep venous thrombosis } \\
\hline Yes & $23(3.8 \%)$ & $21(3.9 \%)$ & $2(3.1 \%)$ & \multirow[t]{2}{*}{0.9} \\
\hline No & $583(95.9 \%)$ & $520(96.1 \%)$ & $63(96.9 \%)$ & \\
\hline \multicolumn{5}{|c|}{ Edema / lymphedema } \\
\hline Yes & $168(27.7 \%)$ & $151(27.9 \%)$ & $17(26.2 \%)$ & \multirow[t]{2}{*}{0.8} \\
\hline No & $438(72.3 \%)$ & $390(72.1 \%)$ & $48(73.8 \%)$ & \\
\hline \multicolumn{5}{|c|}{ Heart failure } \\
\hline Yes & $101(16.7 \%)$ & $90(16.6 \%)$ & $11(16.9 \%)$ & \multirow[t]{2}{*}{1} \\
\hline No & $505(83.3 \%)$ & 451 (83.4\%) & $54(83.1 \%)$ & \\
\hline \multicolumn{5}{|l|}{ Obesity } \\
\hline Yes & $229(37.8 \%)$ & $208(38.4 \%)$ & $21(32.3 \%)$ & \multirow[t]{2}{*}{0.3} \\
\hline No & $377(62.2 \%)$ & $333(61.6 \%)$ & $44(67.7 \%)$ & \\
\hline \multicolumn{5}{|c|}{ Immunosuppression } \\
\hline Yes & $70(11.6 \%)$ & $62(11.5 \%)$ & $8(12.3 \%)$ & \multirow[t]{2}{*}{0.8} \\
\hline No & $536(88.4 \%)$ & $479(88.5 \%)$ & $57(87.7 \%)$ & \\
\hline \multicolumn{5}{|c|}{ Intravenous drug use } \\
\hline Yes & $7(1.2 \%)$ & $7(1.3 \%)$ & $0(0.0 \%)$ & \multirow[t]{2}{*}{1} \\
\hline No & $599(98.8 \%)$ & $534(98.7 \%)$ & $65(100 \%)$ & \\
\hline \multicolumn{5}{|c|}{ HIV infection } \\
\hline Yes & $10(1.7 \%)$ & $10(1.8 \%)$ & $0(0.0 \%)$ & \multirow[t]{2}{*}{0.6} \\
\hline No & $596(98.3 \%)$ & $531(98.2 \%)$ & 65 (100\%) & \\
\hline \multicolumn{5}{|c|}{ Other comorbidities } \\
\hline Yes & $452(74.6 \%)$ & 398 (73.6\%) & $54(83.1 \%)$ & \multirow[t]{2}{*}{0.096} \\
\hline No & 154 (25.4\%) & 143 (26.4\%) & 11 (16.9\%) & \\
\hline
\end{tabular}

Values are expressed as mean $(95 \% \mathrm{Cl})$ or $\%$ as appropriate

presented with "shock", although no information about the origin was provided [8].

Diabetes has been considered a risk factor for bacteremia in cellulitis $[10,11,18]$. Among our diabetic patients $14.4 \%$ developed sepsis, a figure similar to the $16.9 \%$ reported in a large repository database using ICD codes for the subset of diabetics hospitalized with cellulitis/abscess who developed bacteremia/endocarditis/sepsis within the 0-64 age range [18]. Lymphedema has also been considered a predisposing factor for bacteremia [14, 20, 22]. However, $10.1 \%$ of the patients with edema/lymphedema in our series developed sepsis, a figure similar to the $10.7 \%$ observed in the patients as a whole. Recurrent episodes of cellulitis or the existence of wounds or skin lesions were not associated with sepsis in our study.

The bacteremia rate in our cohort was $18.3 \%$ among the patients with blood culture drawn, a value situated in the high range of those previously reported in cellulitis [4-16], although rates of $18.7 \%$ [8] and $21.3 \%$ [9] have been reported in hospitalized patients like ours. Of note is that blood cultures were positive in only $24.4 \%$ of patients with sepsis. Seemingly, prior antibiotic therapy played a major role in this low positivity rate. Thus, many patients were already receiving antibiotics at the time of arrival at the hospital and others, who did not present with sepsis but developed this complication later, may not have undergone blood culture initially, but later when their clinical condition worsened, while were receiving antibiotic therapy. Additional explanations might be untimely blood sampling in patients with intermittent bacteremia or inadequate blood culture drawing or processing. Anyhow sepsis development independently associated with drawing of blood for culture.

All positive blood cultures were monomicrobial, and streptococci were the most commonly isolated pathogen from blood (7.1\% of all blood cultures and $11.1 \%$ among patients with sepsis). Our results agree with most reports that describe streptococci as the most commonly isolated microorganism from blood cultures in SSTI [5-10, 19]. 
Table 2 Clinical, laboratory, imaging and hospitalization parameters associated with sepsis in patients with cellulitis

\begin{tabular}{|c|c|c|c|c|}
\hline & $\begin{array}{l}\text { All } \\
\boldsymbol{n}=606\end{array}$ & $\begin{array}{l}\text { No sepsis } \\
(\boldsymbol{n}=541)\end{array}$ & $\begin{array}{l}\text { Sepsis } \\
(\boldsymbol{n}=65)\end{array}$ & $\boldsymbol{P}$ value \\
\hline \multicolumn{5}{|l|}{ Clinical and topographical aspects } \\
\hline Days of symptoms & $4.11(3.80-4.46)$ & $4.23(3.88-4.61)$ & $3.27(2.65-4.02)$ & 0.04 \\
\hline Temperature $\left({ }^{\circ} \mathrm{C}\right)$ & $37.02(36.94-37.10)$ & $36.98(36.91-37.06)$ & $37.32(37.03-37.62)$ & 0.03 \\
\hline \multicolumn{5}{|l|}{ Location of cellulitis } \\
\hline Lower extremities & $453(74.8 \%)$ & $403(74.5 \%)$ & $50(76.9 \%)$ & \multirow[t]{4}{*}{0.9} \\
\hline Upper extremities & $82(13.5 \%)$ & $74(13.7 \%)$ & $8(12.3 \%)$ & \\
\hline Thorax/abdomen & $26(4.3 \%)$ & $24(4.4 \%)$ & $2(3.1 \%)$ & \\
\hline Head/neck & $45(7.4 \%)$ & $40(7.4 \%)$ & $5(7.7 \%)$ & \\
\hline \multicolumn{5}{|l|}{ Exclusive or preferential side } \\
\hline Right & $264(43.6 \%)$ & $235(43.4 \%)$ & $29(44.6 \%)$ & \multirow[t]{3}{*}{0.5} \\
\hline Left & $292(48.2 \%)$ & $259(47.9 \%)$ & $33(50.8 \%)$ & \\
\hline Bilateral/centered & $50(8.3 \%)$ & $47(8.7 \%)$ & $3(4.6 \%)$ & \\
\hline \multicolumn{5}{|l|}{ Maximum length of cellulitis $(\mathrm{cm})^{b}$} \\
\hline$(n=398)$ & $20.08(18.76-21.50)$ & $19.48(18.13-20.93)$ & $24.85(20.14-30.67)$ & 0.02 \\
\hline \multicolumn{5}{|l|}{ Crepitation } \\
\hline Yes & $9(1.5 \%)$ & $6(1.1 \%)$ & $3(4.6 \%)$ & \multirow[t]{2}{*}{0.06} \\
\hline No & 597 (98.5\%) & 535 (98.9\%) & $62(95.4 \%)$ & \\
\hline \multicolumn{5}{|l|}{ Presence of purulent collection } \\
\hline Yes & $164(27.1 \%)$ & $142(26.2 \%)$ & $22(33.8 \%)$ & \multirow[t]{2}{*}{0.19} \\
\hline No / not detected & 442 (72.9\%) & $399(73.8 \%)$ & $43(66.2 \%)$ & \\
\hline \multicolumn{5}{|l|}{ Detection of the collection } \\
\hline By physical exam & $104(63.4 \%)$ & $91(64.1 \%)$ & $13(59.1 \%)$ & \multirow[t]{2}{*}{0.6} \\
\hline Only by imaging & $60(36.6 \%)$ & $51(35.9 \%)$ & $9(40.9 \%)$ & \\
\hline \multicolumn{5}{|l|}{ Laboratory parameters } \\
\hline Blood glucose (mg/dL) & $124.4(120.9-128.0)$ & $123.3(119.6-127.2)$ & $133.6(123.5-144.5)$ & 0.09 \\
\hline Blood creatinine (mg/dL) & $1.03(1.00-1.07)$ & $1.01(0.97-1.04)$ & $1.28(1.11-1.47)$ & 0.001 \\
\hline Leukocyte count (cells/ $\mu \mathrm{L}$ ) & $10,777(10354-11,218)$ & $10,395(9983-10,824)$ & $14,555(12575-16,847)$ & $<0.0001$ \\
\hline Neutrophil count (\% of leukocytes) & $75.13(73.95-76.34)$ & $74.18(72.92-75.47)$ & $83.55(81.31-85.86)$ & $<0.0001$ \\
\hline \multicolumn{5}{|l|}{$\operatorname{ESR}(\mathrm{mm} / \mathrm{h})$} \\
\hline$(n=161)$ & $53.02(47.64-59.01))$ & $52.84(47.06-59.32)$ & $54.59(41.05-72.59)$ & 0.8 \\
\hline \multicolumn{5}{|l|}{$\mathrm{CRP}(\mathrm{mg} / \mathrm{L})$} \\
\hline$(n=581)$ & $23.60(20.47-27.21)$ & $22.06(18.99-25.63)$ & $41.04(26.52-63.49)$ & 0.008 \\
\hline \multicolumn{5}{|l|}{ Imaging procedures } \\
\hline \multicolumn{5}{|l|}{ Imaging } \\
\hline Yes & $277(45.7 \%)$ & $247(45.7 \%)$ & $30(46.2 \%)$ & \multirow[t]{2}{*}{0.9} \\
\hline No & $329(54.3 \%)$ & $294(54.3 \%)$ & $35(53.8 \%)$ & \\
\hline \multicolumn{5}{|l|}{ Imaging $^{a}$} \\
\hline Only echography & $147(53.1 \%)$ & $136(55.1 \%)$ & $11(36.7 \%)$ & \multirow[t]{4}{*}{0.2} \\
\hline Only CT & $50(18.1 \%)$ & $44(17.8 \%)$ & $6(20.0 \%)$ & \\
\hline Only MRI & $18(6.5 \%)$ & $15(6.1 \%)$ & $3(10.0 \%)$ & \\
\hline Others / combined & $62(22.4 \%)$ & $52(21.1 \%)$ & $10(33.3 \%)$ & \\
\hline \multicolumn{5}{|l|}{ Imaging (single or combined) ${ }^{a}$} \\
\hline Echography & $180(65.0 \%)$ & $160(64.8 \%)$ & 20 (66.7\%) & 0.8 \\
\hline
\end{tabular}


Table 2 Clinical, laboratory, imaging and hospitalization parameters associated with sepsis in patients with cellulitis (Continued)

\begin{tabular}{|c|c|c|c|c|}
\hline & $\begin{array}{l}\text { All } \\
\boldsymbol{n}=606\end{array}$ & $\begin{array}{l}\text { No sepsis } \\
(\boldsymbol{n}=541)\end{array}$ & $\begin{array}{l}\text { Sepsis } \\
(\boldsymbol{n}=65)\end{array}$ & $\boldsymbol{P}$ value \\
\hline Other than echo & $97(35.0 \%)$ & $87(35.2 \%)$ & $10(33.3 \%)$ & \\
\hline$C T$ & $77(27.8 \%)$ & $65(26.3 \%)$ & $12(40.0 \%)$ & 0.11 \\
\hline Other than $\mathrm{CT}$ & $200(72.2 \%)$ & $182(73.7 \%)$ & $18(60.0 \%)$ & \\
\hline MRI & $37(13.3 \%)$ & $30(12.1 \%)$ & $7(23.3 \%)$ & 0.9 \\
\hline Other than MRI & $240(86.6 \%)$ & $217(87.9 \%)$ & $23(76.7 \%)$ & \\
\hline \multicolumn{5}{|c|}{ Hospitalization parameters \& outcome } \\
\hline Days of hospital stay & $7.02(6.63-7.44)$ & $6.88(6.49-7.30)$ & $8.30(6.72-10.25)$ & 0.09 \\
\hline \multicolumn{5}{|l|}{ Follow-up after discharge } \\
\hline Primary care & $377(63.7 \%)$ & $345(64.6 \%)$ & $32(55.2 \%)$ & 0.3 \\
\hline Outpatient clinic & $202(34.1 \%)$ & $177(33.1 \%)$ & $25(43.1 \%)$ & \\
\hline Others & $13(2.2 \%)$ & $12(2.2 \%)$ & $1(1.7 \%)$ & \\
\hline \multicolumn{5}{|l|}{ Cellulitis outcome } \\
\hline Good response & $520(85.8 \%)$ & $469(86.7 \%)$ & $51(78.5 \%)$ & 0.07 \\
\hline Poor response & $86(14.2 \%)$ & $72(13.3 \%)$ & $14(21.5 \%)$ & \\
\hline \multicolumn{5}{|l|}{ Vital outcome } \\
\hline Death & $18(3.0 \%)$ & $11(2.0 \%)$ & $7(10.8 \%)$ & 0.001 \\
\hline Survival & 588 (97.0\%) & $530(98.0 \%)$ & $58(89.2 \%)$ & \\
\hline \multicolumn{5}{|l|}{ Death related to cellulitis } \\
\hline Yes & $5(27.8 \%)$ & $1(9.1 \%)$ & $4(57.1 \%)$ & 0.047 \\
\hline No & $13(72.2 \%)$ & 10 (90.9\%) & $3(42.9 \%)$ & \\
\hline Days from admission to death & $7.18(4.14-12.45)$ & $9.05(4.85-16.88)$ & $5.16(1.54-17.23)$ & 0.3 \\
\hline
\end{tabular}

Values are expressed as mean $(95 \% \mathrm{Cl})$ or \% as appropriate

${ }^{\text {a }}$ Respect to patients who underwent imaging procedures

Overall, the causative microorganism was identified, either in pus or blood, in about one-fourth of the patients in our study, reaching $40.0 \%$ in patients with sepsis. Community-acquired MRSA infection rate is increasing, particularly in SSTI. A study from Hawaii, one of the world places with higher MRSA prevalence, reported $62 \%$ of MRSA isolates in patients with abscesses or skin ulcers [26], data from the USA points out to figures of at least $50 \%[22,27,28]$, and this agent was isolated in $13-22 \%$ of patients from Spain [25, 29]. In our multicenter series, MRSA was identified in $24.6 \%$ of all pure or mixed isolates of $S$. aureus in either blood or pus (9.8\% of all patients with positive cultures). Although the absolute number of MRSA infections in our series is too low to draw definite conclusions, MRSA does not seem to be more prone to the development of sepsis than other agents.

Not unexpectedly, sepsis associated with mortality in our study. In fact, the mortality rates, both overall and those caused by the infection, were five-fold higher in septic than in non-septic patients, reaching $10.8 \%$ overall and $57.1 \%$ when analyzing the deaths directly related to cellulitis. This mortality rate is consistent with the in-hospital mortality $>10 \%$ reported for sepsis and $>40 \%$ for septic shock by the Third International Consensus Definitions for Sepsis and Septic Shock working group [24].

The lack of studies on sepsis in cellulitis precludes any comparison. However, a study focused on the comparison of cellulitis with necrotizing fasciitis in patients admitted to an intensive care unit reported an in-hospital or 30 -day mortality rate as high as $56.5 \%(13 / 23$ patients) for cellulitis and 64.5\% (20/31 patients) for necrotizing fasciitis [3]. Another study reported an overall 30day mortality of $4.8 \%$ in patients with cellulitis, and a mortality rate due to shock or multiorgan failure of $3.0 \%$ [8]. Five out of our 65 patients with sepsis $(7.7 \%)$ developed septic shock, and 3 of them died. In the above mentioned study, septic shock developed in 30 and 61\% of the patients with cellulitis or necrotizing fasciitis, respectively [3].

Sepsis was also associated with increased blood leukocyte counts, as expected in the setting of systemic inflammatory response syndrome (SIRS) [24]. It also associated with high serum creatinine levels, which seems be due to the renal dysfunction commonly observed in sepsis [24], although certain degree of previous renal insufficiency in some patients as a predisposing factor for cellulitis and/or sepsis cannot be completely ruled out. 
Table 3 Microbiological aspects associated with sepsis in patients with cellulitis

\begin{tabular}{|c|c|c|c|c|}
\hline & $\begin{array}{l}\text { All } \\
\boldsymbol{n}=606\end{array}$ & $\begin{array}{l}\text { No sepsis } \\
(\boldsymbol{n}=541)\end{array}$ & $\begin{array}{l}\text { Sepsis } \\
(\boldsymbol{n}=65)\end{array}$ & $\boldsymbol{P}$ value \\
\hline \multicolumn{5}{|c|}{ Culture of the purulent collection } \\
\hline \multicolumn{5}{|l|}{ Pus culture available } \\
\hline Yes & $150(24.8 \%)$ & $129(23.8 \%)$ & $21(32.3 \%)$ & \multirow[t]{2}{*}{0.14} \\
\hline No & $456(75.2 \%)$ & $412(76.2 \%)$ & $44(67.7 \%)$ & \\
\hline \multicolumn{5}{|l|}{ Results of culture } \\
\hline Positive & $118(78.7 \%)$ & $101(78.3 \%)$ & $17(81.0 \%)$ & \multirow[t]{2}{*}{0.8} \\
\hline Negative & $32(21.3 \%)$ & $28(21.7 \%)$ & $4(19.0 \%)$ & \\
\hline \multicolumn{5}{|l|}{ Positive culture } \\
\hline Monomicrobial & $92(78.0 \%)$ & $78(77.2 \%)$ & $14(82.4 \%)$ & \multirow[t]{2}{*}{0.7} \\
\hline Polymicrobial & $26(22.0 \%)$ & $23(22.8 \%)$ & $3(17.6 \%)$ & \\
\hline \multicolumn{5}{|l|}{ Aerobes (monomicrobial) * } \\
\hline None & $32(21.3 \%)$ & $28(21.7 \%)$ & $4(19.0 \%)$ & \multirow[t]{5}{*}{0.6} \\
\hline S aureus only & $45(30.0 \%)$ & $41(31.8 \%)$ & $4(19.0 \%)$ & \\
\hline Streptococci only & $18(12.0 \%)$ & $14(10.9 \%)$ & $4(19.0 \%)$ & \\
\hline Gram-neg bacilli only & $21(14.0 \%)$ & $17(13.2 \%)$ & $4(19.0 \%)$ & \\
\hline Others/polymicrobial & $34(22.7 \%)$ & $29(22.5 \%)$ & $5(23.8 \%)$ & \\
\hline \multicolumn{5}{|c|}{ Aerobes (mono or polymicrobial) * } \\
\hline S aureus & $56(37.3 \%)$ & $51(39.5 \%)$ & $5(23.8 \%)$ & \multirow[t]{2}{*}{0.17} \\
\hline No $S$ aureus & $94(62.7 \%)$ & $78(60.5 \%)$ & $16(76.2 \%)$ & \\
\hline Streptococci & $24(16.0 \%)$ & $20(15.5 \%)$ & $4(19.0 \%)$ & \multirow[t]{2}{*}{0.7} \\
\hline No streptococci & $126(84.0 \%)$ & $109(84.5 \%)$ & $17(81.0 \%)$ & \\
\hline Gram-negative bacilli & $43(28.7 \%)$ & 37 (28.7\%) & $6(28.6 \%)$ & \multirow[t]{2}{*}{1} \\
\hline No Gram-neg bacilli & 107 (71.3\%) & $92(71.3 \%)$ & $15(71.4 \%)$ & \\
\hline \multicolumn{5}{|l|}{ Anaerobes * } \\
\hline Yes & $8(5.3 \%)$ & $6(4.7 \%)$ & $2(9.5 \%)$ & \multirow[t]{2}{*}{0.3} \\
\hline No & $142(94.7 \%)$ & $123(95.3 \%)$ & 19 (90.5\%) & \\
\hline \multicolumn{5}{|l|}{ Blood culture } \\
\hline \multicolumn{5}{|l|}{ Blood culture available } \\
\hline Yes & $252(41.6 \%)$ & 207 (38.3\%) & 45 (69.2\%) & \multirow[t]{2}{*}{$<0.0001$} \\
\hline No & $354(58.4 \%)$ & $334(61.7 \%)$ & $20(30.8 \%)$ & \\
\hline \multicolumn{5}{|l|}{ Results of culture } \\
\hline Positive & $46(18.3 \%)$ & 35 (16.9\%) & $11(24.4 \%)$ & \multirow[t]{2}{*}{0.2} \\
\hline Negative & $206(81.7 \%)$ & $172(83.1 \%)$ & $34(75.6 \%)$ & \\
\hline \multicolumn{5}{|l|}{ Positive culture } \\
\hline Monomicrobial & $46(100 \%)$ & $35(100 \%)$ & $11(100 \%)$ & \multirow[t]{2}{*}{-} \\
\hline Polymicrobial & $0(0.0 \%)$ & $0(0.0 \%)$ & $0(0.0 \%)$ & \\
\hline \multicolumn{5}{|l|}{ Aerobes ** } \\
\hline None & $206(81.7 \%)$ & $172(83.1 \%)$ & $34(75.6 \%)$ & \multirow[t]{5}{*}{0.7} \\
\hline S aureus & $8(3.2 \%)$ & $7(3.4 \%)$ & $1(2.2 \%)$ & \\
\hline Streptococci & $18(7.1 \%)$ & $13(6.3 \%)$ & $5(11.1 \%)$ & \\
\hline Gram-neg bacilli & $7(2.8 \%)$ & $5(2.4 \%)$ & $2(4.4 \%)$ & \\
\hline Others & $13(5.2 \%)$ & $10(4.8 \%)$ & $3(6.7 \%)$ & \\
\hline
\end{tabular}

Anaerobes 
Table 3 Microbiological aspects associated with sepsis in patients with cellulitis (Continued)

\begin{tabular}{|c|c|c|c|c|}
\hline & $\begin{array}{l}\text { All } \\
\boldsymbol{n}=606\end{array}$ & $\begin{array}{l}\text { No sepsis } \\
(\boldsymbol{n}=541)\end{array}$ & $\begin{array}{l}\text { Sepsis } \\
(\boldsymbol{n}=65)\end{array}$ & $\boldsymbol{P}$ value \\
\hline Yes & $1(0.4 \%)$ & $0(0.0 \%)$ & $1(2.2 \%)$ & 0.18 \\
\hline No & $251(99.6 \%)$ & $207(100 \%)$ & $44(97.8 \%)$ & \\
\hline \multicolumn{5}{|l|}{ Pus or blood culture } \\
\hline \multicolumn{5}{|l|}{ Any culture } \\
\hline Yes & $333(55.0 \%)$ & $282(47.9 \%)$ & $51(78.5 \%)$ & 0.0001 \\
\hline No & $273(45.0 \%)$ & $259(47.9 \%)$ & $14(21.5 \%)$ & \\
\hline \multicolumn{5}{|c|}{ Any microorganism identified } \\
\hline Yes & $155(25.6 \%)$ & $129(23.8 \%)$ & $26(40.0 \%)$ & 0.005 \\
\hline No & $451(74.4 \%)$ & $412(76.2 \%)$ & $39(60.0 \%)$ & \\
\hline \multicolumn{5}{|c|}{ Specific microorganisms *** } \\
\hline None & $178(53.5 \%)$ & $153(54.3 \%)$ & $25(49.0 \%)$ & 0.4 \\
\hline S aureus only & $50(15.0 \%)$ & $45(16.0 \%)$ & $5(9.8 \%)$ & \\
\hline Streptococci only & $33(9.9 \%)$ & $25(8.9 \%)$ & $8(15.7 \%)$ & \\
\hline Gram-neg bacilli only & $28(8.4 \%)$ & $22(7.8 \%)$ & $6(11.8 \%)$ & \\
\hline Others/polymicrobial & $44(13.2 \%)$ & $37(13.1 \%)$ & $7(13.7 \%)$ & \\
\hline \multicolumn{5}{|c|}{ Aerobes (mono or polymicrobial) *** } \\
\hline S aureus & $61(18.3 \%)$ & 55 (19.5\%) & $6(11.8 \%)$ & 0.19 \\
\hline No $S$ aureus & $272(81.7 \%)$ & $227(80.5 \%)$ & $45(88.2 \%)$ & \\
\hline Streptococci & $40(12.0 \%)$ & $31(11.0 \%)$ & $9(17.6 \%)$ & 0.18 \\
\hline No streptococci & $293(88.0 \%)$ & $251(89.0 \%)$ & $42(82.4 \%)$ & \\
\hline Gram-negative bacilli & $50(15.0 \%)$ & $42(14.9 \%)$ & $8(15.7 \%)$ & 0.9 \\
\hline No Gram-neg bacilli & $283(85.0 \%)$ & $240(85.1 \%)$ & $43(84.3 \%)$ & \\
\hline \multicolumn{5}{|c|}{ Causative microorganisms identified } \\
\hline Yes & $143(23.6 \%)$ & $120(22.2 \%)$ & $23(35.4 \%)$ & 0.006 \\
\hline No & $453(74.8 \%)$ & $414(76.5 \%)$ & $39(60.0 \%)$ & \\
\hline Doubtful & $10(1.7 \%)$ & $7(1.3 \%)$ & $3(4.6 \%)$ & \\
\hline
\end{tabular}

* Respect to all patients with pus $\left({ }^{*}\right)$, blood $\left({ }^{* *}\right)$ or any $\left({ }^{* *}\right)$ culture

Patients with sepsis received more intensive medical and surgical treatment than those not septic during hospitalization. Sepsis was also associated with modification of the initial antimicrobial regimen in the multivariate analysis, mainly due to poor response to the initial treatment. Therefore, it seems clear that the severity of the infection, and the unsatisfactory response obtained, led to the attending physicians to change the initial therapeutic regimen.

Finally, and interestingly, sepsis associated with the extent of the cellulitis area. Once again, the lack of studies on this topic precludes contrasting our observation with other experiences. However, a study on limb cellulitis found in the univariate analyses an increased risk of bacteremia in patients with extension to the whole limb, the proximal limb, and the trunk, although only proximal limb involvement remained predictive in the multivariate analysis [9]. This association between the extent of the infection and the risk of bacteremia and sepsis makes sense, and suggests that the dimension of the infectious area should be registered in the patient's medical record, and that patients with large cellulitis areas should be particularly monitored for the development of this serious and potentially lethal complication.

The main strengths of our study are the large sample size, its prospective nature and the elevated number of parameters evaluated, which allowed to adjust for and minimize the effect of confounders. Limitations include the absence of a unified treatment protocol, which would allow the evaluation of the responses to the same treatment, and the variability characteristic of multicenter studies, particularly regarding procedural and management aspects. However, currently no single or widely accepted treatment protocol exists $[3,17,19-21]$, considering the great diversity of clinical and microbiological issues related to cellulitis, and the multicenter character of the study allows the evaluation of the real clinical practice across our country, minimizing potential biases from a single institution. 
Table 4 Treatment characteristics associated with sepsis in patients with cellulitis

\begin{tabular}{|c|c|c|c|c|}
\hline & $\begin{array}{l}\text { All } \\
\boldsymbol{n}=606\end{array}$ & $\begin{array}{l}\text { No sepsis } \\
(\boldsymbol{n}=541)\end{array}$ & $\begin{array}{l}\text { Sepsis } \\
(\boldsymbol{n}=65)\end{array}$ & $\boldsymbol{P}$ value \\
\hline \multicolumn{5}{|l|}{ Treatment before admission } \\
\hline Yes & $237(39.1 \%)$ & $218(40.3 \%)$ & $19(29.2 \%)$ & \multirow[t]{2}{*}{0.08} \\
\hline No & $369(60.9 \%)$ & $323(59.7 \%)$ & $46(70.8 \%)$ & \\
\hline \multicolumn{5}{|l|}{ Initial treatment at admission } \\
\hline Single antibiotic & $381(62.9 \%)$ & $347(64.1 \%)$ & $34(52.3 \%)$ & \multirow[t]{2}{*}{0.06} \\
\hline$>1$ antibiotic & $225(37.1 \%)$ & $194(35.9 \%)$ & $31(47.7 \%)$ & \\
\hline \multicolumn{5}{|l|}{ Amoxicillin-clavulanate monotherapy } \\
\hline Yes & $259(42.7 \%)$ & $231(42.7 \%)$ & $28(43.1 \%)$ & \multirow[t]{2}{*}{1} \\
\hline No & $347(57.3 \%)$ & $310(57.3 \%)$ & 37 (56.9\%) & \\
\hline \multicolumn{5}{|l|}{ Change of the initial regimen } \\
\hline Yes & $184(30.4 \%)$ & $148(27.4 \%)$ & $36(55.4 \%)$ & \multirow[t]{2}{*}{$<0.0001$} \\
\hline No & $422(69.6 \%)$ & $393(72.6 \%)$ & $29(44.6 \%)$ & \\
\hline \multicolumn{5}{|l|}{ Reason for change ${ }^{a}$} \\
\hline Culture & $57(31.0 \%)$ & $46(31.1 \%)$ & $11(30.6 \%)$ & \multirow[t]{4}{*}{0.3} \\
\hline Poor response & 55 (29.9\%) & $40(27.0 \%)$ & $15(41.7 \%)$ & \\
\hline Toxicity & $11(6.0 \%)$ & $9(6.1 \%)$ & $2(5.6 \%)$ & \\
\hline Others & $61(33.2 \%)$ & $53(35.8 \%)$ & $8(22.2 \%)$ & \\
\hline Days until change ${ }^{a}$ & $3.49(3.16-3.85)$ & $3.40(3.05-3.79)$ & $3.86(3.02-4.94)$ & 0.3 \\
\hline \multicolumn{5}{|l|}{ Treatment after change ${ }^{a}$} \\
\hline Single antibiotic & $86(46.7 \%)$ & $71(48.0 \%)$ & $15(41.7 \%)$ & \multirow[t]{2}{*}{0.5} \\
\hline$>1$ antibiotic & $98(53.3 \%)$ & 77 (52.0\%) & $21(58.3 \%)$ & \\
\hline \multicolumn{5}{|l|}{ Antibiotic treatment after discharge } \\
\hline Yes & $504(85.1 \%)$ & $453(84.8 \%)$ & $51(87.9 \%)$ & \multirow[t]{2}{*}{0.5} \\
\hline No & $88(14.9 \%)$ & $81(15.2 \%)$ & $7(12.1 \%)$ & \\
\hline \multicolumn{5}{|l|}{ Treatment after discharge } \\
\hline Single antibiotic & $407(80.8 \%)$ & $368(81.2 \%)$ & $39(76.5 \%)$ & \multirow[t]{2}{*}{0.4} \\
\hline$>1$ antibiotic & 97 (19.2\%) & $85(18.8 \%)$ & $12(23.5 \%)$ & \\
\hline Total number of antibiotics used & $1.59(1.53-1.65)$ & $1.55(1.49-1.61)$ & $2.02(1.78-2.28)$ & $<0.0001$ \\
\hline \multicolumn{5}{|l|}{ Total number of antibiotics used } \\
\hline 1 & $289(47.7 \%)$ & $271(50.1 \%)$ & $18(27.7 \%)$ & \multirow[t]{5}{*}{0.0002} \\
\hline 2 & $191(31.5 \%)$ & $169(31.2 \%)$ & $22(33.8 \%)$ & \\
\hline 3 & 89 (14.7\%) & $74(13.7 \%)$ & $15(23.1 \%)$ & \\
\hline 4 & $35(5.8 \%)$ & $25(4.6 \%)$ & $10(15.4 \%)$ & \\
\hline 5 & $2(0.3 \%)$ & $2(0.4 \%)$ & $0(0.0 \%)$ & \\
\hline Days of IV antibiotic treatment & $6.14(5.78-6.52)$ & $6.00(5.63-6.38)$ & $7.48(6.05-9.26)$ & 0.03 \\
\hline Total days of antibiotic treatment & $13.27(12.70-13.87)$ & $13.11(12.54-13.71)$ & $14.72(12.39-17.50)$ & 0.19 \\
\hline \multicolumn{5}{|l|}{ Surgical treatment } \\
\hline Yes & $81(13.4 \%)$ & $66(12.2 \%)$ & $15(23.1 \%)$ & \multirow[t]{2}{*}{0.01} \\
\hline No & $525(86.6 \%)$ & $475(87.8 \%)$ & $50(76.9 \%)$ & \\
\hline
\end{tabular}

Values are expressed as mean $(95 \% \mathrm{Cl})$ or $\%$ as appropriate

a Only in patients who underwent treatment modification respect to the initial regimen 
Table $\mathbf{5}$ Variables independently associated with sepsis in patients with cellulitis

\begin{tabular}{lll}
\hline & OR (95\% Cl) & $P$ \\
\hline Leukocyte counts (per 1000 cells/ML) & $1.080(1.026-1.137)$ & 0.003 \\
Serum creatinine (per mg/dL) & $2.238(1.378-3.637)$ & 0.001 \\
Blood culture available & $2.984(1.443-6.169)$ & 0.003 \\
Modification of the initial antibiotic regimen & $2.154-1.068-4.347)$ & 0.03 \\
Maximum length of cellulitis (per cm) & $1.029(1.009-1.049)$ & 0.004 \\
\hline
\end{tabular}

\section{Conclusions}

From our large study, the first carried out on this topic, we conclude that blood culture drawing and modification of the initial antimicrobial regimen were more frequently observed in patients who developed sepsis. Similarly, blood leukocytes, creatinine, and the extent of cellulitis were also independently associated with sepsis development, and these three easily available parameters might be useful to identify those patients prone to develop sepsis and to optimize their management.

\section{Abbreviations}

Cl: Confidence interval; CRP: C-reactive protein; HUCA: Hospital Universitario Central de Asturias; IDSA: Infectious Diseases Society of America; MRSA: Methicillin-resistant Staphylococcus aureus; SIRS: Systemic inflammatory response syndrome; SSTI: Skin and soft tissue infection

\section{Acknowledgements}

These results were presented in part at the IDWeek 2018, San Francisco, CA, USA, October 3-7th, 2018, Abstract 69266.

\section{Authors' contributions}

$\mathrm{BDF}, \mathrm{AG}, \mathrm{HG}, \mathrm{CM}, \mathrm{HE}$; PS, MA, ILC, MMR, AMA, JG, and MB recruited patients and collected the data, JC designed the study data file, did the statistical analysis of the data and edited the manuscript, JDF, and AA recruited patients, collected data and revised the first draft of the manuscript, VA designed the study, recruited patients, collected data and wrote the manuscript. All authors have read and approved the manuscript.

\section{Authors Information}

On behalf of the Working Group of Infectious Diseases of the Spanish Society of Internal Medicine (SEMI).

\section{Funding}

The authors thank the Infectious Diseases Working Group of the Spanish Society of Internal Medicine (SEMI) for helping promoting and funding this study.

\section{Availability of data and materials}

The datasets generated and analysed during the current study are not publicly available due to privacy but are available from the corresponding author on reasonable request.

\section{Ethics approval and consent to participate}

This was an observational study, using anonymized data, in which the patients underwent routine clinical care for cellulitis, without any change in its management or specific determinations or procedures. Therefore, no formal written informed consent was obtained from the patients. The Research Ethics Committee of the Principality of Asturias granted a formal waiver of ethical approval for this study.

\section{Consent for publication}

Not applicable.

\section{Competing interests}

The authors declare that they have no competing interests.

\section{Author details}

${ }^{1}$ Infectious Diseases Unit, Hospital de Galdácano, Vizcaya, Spain. ${ }^{2}$ Infectious Diseases Unit, Hospital de Cabueñes, Gijón, Spain. ${ }^{3}$ Internal Medicine Service, Hospital de Povisa, Vigo, Spain. ${ }^{4}$ Infectious Diseases Unit, Hospital Universitario Central de Asturias, Oviedo, Spain. ${ }^{5}$ Internal Medicine Service, Hospital Dr Peset, Valencia, Spain. ${ }^{6}$ Internal Medicine Service, Complejo Hospitalario de León, León, Spain. ' Infectious Diseases Unit, Hospital La Fe, Valencia, Spain. ${ }^{8}$ Group of Translational Research in Infectious Diseases, Instituto de Investigación Sanitaria del Principado de Asturias (ISPA), Oviedo, Spain.

Received: 5 May 2019 Accepted: 21 February 2020

Published online: 12 March 2020

\section{References}

1. Miller LG, Eisenberg DF, Liu H, Chang CL, Wang Y, Luthra R, Wallace A, Fang C, Singer J, Suaya JA. Incidence of skin and soft tissue infections in ambulatory and inpatient settings, 2005-2010. BMC Infect Dis. 2015;15:362.

2. Goettsch WG, Bouwes Bavinck JN, Herings RM. Burden of illness of bacterial cellulitis and erysipelas of the leg in the Netherlands. J Eur Acad Dermatol Venereol. 2006:20:834-9.

3. Cranendonk DR, Lavrijsen APM, Prins JM, Wiersinga WJ. Cellulitis: current insights into pathophysiology and clinical management. Neth J Med. 2017; 75:366-78.

4. Torres J, Avalos N, Echols L, Mongelluzzo J, Rodriguez RM. Low yield of blood and wound cultures in patients with skin and soft-tissue infections. Am J Emerg Med. 2017;35:1159-61.

5. Gunderson CG, Martinello RA. A systematic review of bacteremias in cellulitis and erysipelas. J Inf Secur. 2012;64:148-55.

6. Perl B, Gottehrer NP, Raveh D, Schlesinger Y, Rudensky B, Yinnon AM. Costeffectiveness of blood cultures for adult patients with cellulitis. Clin Infect Dis. 1999;29:1483-8.

7. Cranendonk DR, van Vught LA, Wiewel MA, Cremer OL, Horn J, Bonten MJ, Schultz MJ, van der Poll T, Wiersinga WJ. Clinical characteristics and outcomes of patients with cellulitis requiring intensive care. JAMA Dermatol. 2017;153:578-82.

8. Carratalà J, Rosón B, Fernández-Sabé N, Shaw E, del Rio O, Rivera A, Gudiol F. Factors associated with complications and mortality in adult patients hospitalized for infectious cellulitis. Eur J Clin Microbiol Infect Dis. 2003;22:151-7.

9. Peralta G, Padrón E, Roiz MP, De Benito I, Garrido JC, Talledo F, RodríguezLera MJ, Ansorena L, Sánchez MB. Risk factors for bacteremia in patients with limb cellulitis. Eur J Clin Microbiol Infect Dis. 2006;25:619-26.

10. Bauer S, Aubert CE, Richli M, Chuard C. Blood cultures in the evaluation of uncomplicated cellulitis. Eur J Intern Med. 2016;36:50-6.

11. Lasa JS, Fernández Recalde ML, Finn BC, Bruetman JE, Peroni J, Young P. Bacteriemia en pacientes internados con celulitis. Medicina (Buenos Aires). 2011;71:298-304.

12. Paolo WF, Poreda AR, Grant W, Scordino D, Wojcik S. Blood culture results do not affect treatment in complicated cellulitis. J Emerg Med. 2013;45:163-7.

13. van Daalen FV, Kallen MC, van den Bosch CMA, Hulscher MEJL, Geerlings SE, Prins JM. Clinical condition and comorbidity as determinants for blood culture positivity in patients with skin and soft-tissue infections. Eur J Clin Microbiol Infect Dis. 2017;36:1853-8.

14. Tay EY, Thirumoorthy T, Pang SM, Lee HY. Clinical outcomes of bacteraemia in cellulitis of the leg. Clin Exp Dermatol. 2014;39:683-8.

15. Lee CY, Kunin CM, Chang C, Lee SS, Chen YS, Tsai HC. Development of a prediction model for bacteremia in hospitalized adults with cellulitis to aid in the efficient use of blood cultures: a retrospective cohort study. BMC Infect Dis. 2016;16:581.

16. Lipsky BA, Kollef MH, Miller LG, Sun X, Johannes RS, Tabak YP. Predicting bacteremia among patients hospitalized for skin and skin-structure infections: derivation and validation of a risk score. Infect Control Hosp Epidemiol. 2010;31:828-37.

17. Stevens DL, Bisno AL, Chambers HF, Dellinger EP, Goldstein EJ, Gorbach SL, et al. Practice guidelines for the diagnosis and management of skin and soft tissue infections: 2014 update by the Infectious Diseases Society of America. Clin Infect Dis. 2014;59:e10-52. 
18. Suaya JA, Eisenberg DF, Fang C, Miller LG. Skin and soft tissue infections and associated complications among commercially insured patients aged 0-64 years with and without diabetes in the U.S. PLoS One. 2013;8:e60057.

19. Raff AB, Kroshinsky D. Cellulitis: a review. JAMA. 2016;316:325-37.

20. Swartz MN. Cellulitis. New Engl J Med. 2004;350:904-12.

21. Montravers P, Snauwaert A, Welsch C. Current guidelines and recommendations for the management of skin and soft tissue infections. Curr Opin Infect Dis. 2016;29:131-8.

22. Bystritsky R, Chambers H. Cellulitis and soft tissue infections. Ann Intern Med. 2018;168:TTC17-32.

23. Bone RC, Balk RA, Cerra FB, Dellinger RP, Fein AM, Knaus WA, Schein RM, Sibbald WJ. Definitions for sepsis and organ failure and guidelines for the use of innovative therapies in sepsis. Chest. 1992;101:1644-55.

24. Singer M, Deutschman CS, Seymour CW, Shankar-Hari M, Annane D, Bauer $M$, et al. The third international consensus definitions for sepsis and septic shock (Sepsis-3). JAMA. 2016;315:801-10.

25. Raya-Cruz M, Ferullo I, Arrizabalaga-Asenjo M, Nadal-Nadal A, Díaz-Antolín MP, Garau-Colom M, Payeras-Cifre A. Infecciones de piel y partes blandas en pacientes hospitalizados: factores epidemiológicos, microbiológicos, clínicos y pronósticos. Enferm Infecc Microbiol Clin. 2014;32:152-9.

26. Khawcharoenporn T, Tice AD, Grandinetti A, Chow D. Risk factors for community-associated methicillin-resistant Staphylococcus aureus cellulitis and the value of recognition. Hawaii Med J. 2010;69:232-6.

27. Daum RS. Clinical practice. Skin and soft-tissue infections caused by methicillin-resistant Staphylococcus aureus. N Engl J Med. 2007;357:380-90.

28. Moran GJ, Krishnadasan A, Gorwitz RJ, Fosheim GE, McDougal LK, Carey RB, et al. Methicillin-resistant $\mathrm{S}$. aureus infections among patients in the emergency department. N Engl J Med. 2006;355:666-74.

29. Casado-Verrier B, Gómez-Fernández C, Paño-Pardo JR, Gómez-Gil R, Mingorance-Cruz J, Moreno-Alonso de Celada R, et al. Prevalencia de infecciones de piel y tejidos blandos producidas por Staphyloccus aureus resistente a meticilina comunitario en Madrid [community-adquired methicillin resistant Staphylococcus aureus skin and soft tissue infections in Madrid: prevalence study]. Enferm Infecc Microbiol Clin. 2012;30:300-6

\section{Publisher's Note}

Springer Nature remains neutral with regard to jurisdictional claims in published maps and institutional affiliations.

Ready to submit your research? Choose BMC and benefit from:

- fast, convenient online submission

- thorough peer review by experienced researchers in your field

- rapid publication on acceptance

- support for research data, including large and complex data types

- gold Open Access which fosters wider collaboration and increased citations

- maximum visibility for your research: over $100 \mathrm{M}$ website views per year

At $\mathrm{BMC}$, research is always in progress.

Learn more biomedcentral.com/submissions 